\title{
ARTICLE
}

Received 4 Nov 2014 | Accepted 3 Mar 2015 | Published 20 Apr 2015

DOI: $10.1038 /$ ncomms 7829

OPEN

\section{The desensitization gate of inhibitory Cys-loop receptors}

Marc Gielen ${ }^{1} \dagger$, Philip Thomas $^{1} \&$ Trevor G. Smart ${ }^{1}$

Cys-loop neurotransmitter-gated ion channels are vital for communication throughout the nervous system. Following activation, these receptors enter into a desensitized state in which the ion channel shuts even though the neurotransmitter molecules remain bound. To date, the molecular determinants underlying this most fundamental property of Cys-loop receptors have remained elusive. Here we present a generic mechanism for the desensitization of Cys-loop $\mathrm{GABA}_{A}\left(\mathrm{GABA} \mathrm{A}_{\mathrm{A} s}\right.$ ) and glycine receptors (GlyRs), which both mediate fast inhibitory synaptic transmission. Desensitization is regulated by interactions between the second and third transmembrane segments, which affect the ion channel lumen near its intracellular end. The $G_{A B A} R$ and GlyR pore blocker picrotoxin prevented desensitization, consistent with its deep channel-binding site overlapping a physical desensitization gate.

\footnotetext{
${ }^{1}$ Department of Neuroscience, Physiology \& Pharmacology, University College London, Gower Street, London WC1E 6BT, UK. †Present address: Institut Pasteur, Channel-Receptor Unit, 25 rue du Docteur Roux, 75724 Paris, France. Correspondence and requests for materials should be addressed to T.G.S. (email: t.smart@ucl.ac.uk) or to M.G. (email: marc.gielen@pasteur.fr).
} 
T he presynaptic release of neurotransmitters is a prelude to their diffusion across the synaptic cleft and subsequent activation of postsynaptic ionotropic receptors, which are responsible for fast chemical neurotransmission. Agonist binding initiates the rapid opening of ligand-gated ion channels permitting a selective flow of ions through the pore. The sustained presence of the neurotransmitter will cause ligand-gated channels to transit from the active open-channel agonist-bound conformation to a desensitized shut-channel, agonist-bound state, thereby limiting current flow ${ }^{1,2}$. Receptor desensitization is a fundamental property of most ligand-gated ion channels and can have profound physiological consequences. These include the progressive reduction of postsynaptic current on repetitive synaptic neurotransmitter release ${ }^{2-5}$; the predesensitization of receptors by low ambient concentrations of neurotransmitter due to spillover from active neighbouring synapses $^{6}$; and the slowing of synaptic current decays leading to their prolongation ${ }^{5}$.

In the central nervous system, neuronal activity results from a balance between excitation and inhibition. This is largely dictated by the activity of excitatory ionotropic glutamate receptors, and inhibition caused by GABA and glycine ${ }^{7}$ activating $\mathrm{GABA}_{\mathrm{A}}$ $\left(\mathrm{GABA}_{\mathrm{A}} \mathrm{Rs}\right)$ and glycine receptors (GlyRs). These latter receptors belong to the superfamily of pentameric Cys-loop receptors that also comprises excitatory nicotinic acetylcholine (nAChRs) and serotonin receptors $\left(5 \mathrm{HT}_{3} \mathrm{R}\right)^{7}$. Differential desensitization kinetics of excitatory and inhibitory receptors has the potential to profoundly affect the spike firing profiles of neurons ${ }^{5}$ and thus neural network activity. At the molecular level, desensitization of AMPA and kainate classes of ionotropic GluRs is relatively well understood and involves structural rearrangements at the dimer interface between adjacent extracellular agonist-binding domains ${ }^{8-11}$. However, for the Cys-loop $\mathrm{GABA}_{\mathrm{A}} \mathrm{Rs}$ and GlyRs, although the structure-function studies have improved our understanding of how these receptors activate ${ }^{7,12}$, the molecular determinants underlying the process of desensitization have yet to be defined.

Here we show that for the inhibitory neurotransmitter $\mathrm{GABA}_{\mathrm{A}}$ and glycine receptors, the mechanism of agonist-induced desensitization is regulated by residue interactions between the transmembrane domains of the receptor, resulting in a timedependent constriction of the ion channel pore that reduces the agonist-activated membrane conductance. This constriction has the characteristics of a desensitization 'gate' that is discrete from the ion channel gate involved in ligand-gated channel opening.

\section{Results}

Desensitization profiles differ between $\mathrm{GABA}_{\mathrm{A}}$ receptors. To locate the molecular components responsible for desensitization, we selected two $\mathrm{GABA}_{\mathrm{A}} \mathrm{R}$ isoforms that differ markedly in their response to supersaturating GABA concentrations $(10 \mathrm{mM})$ by either desensitizing significantly $(\alpha 1 \beta 2$ heteromers; percentage of peak current desensitization ( $\%$ Des $)=86 \%$ and weighted decay time constant $\left(\tau_{\mathrm{W}}\right)=17 \mathrm{~s}$ ) or minimally ( $\rho 1$ homomers, $19 \%$ Des and $23 \mathrm{~s}$, Table 1, Fig. 1a). We then constructed chimeras to first explore the role of the extracellular domain (ECD) by replacing the ECD of $\alpha 1$ with the homologous section from $\rho 1\left(\rho 1^{\Delta 260}-\alpha 1\right.$; Supplementary Fig. 1). The desensitization profile was similar to that observed for wild-type $\alpha 1 \beta 2$ receptors (Fig. 1a), consistent with published data ${ }^{13}$. Next we built chimeras containing M1 to M4 and the intracellular linkers (M1-M2 and M3-M4) from $\rho 1$, coupled to the entire extracellular region of $\alpha 1$ or $\beta 2$, corresponding to their ECDs and the external M2-M3 linkers (chimeras $\alpha 1^{\mathrm{EXT}}-\rho 1^{\mathrm{TM}}+\mathrm{INT}$ and $\beta 2^{\mathrm{EXT}}-\rho 1^{\mathrm{TM}+\mathrm{INT}}$, respectively; Supplementary Fig. 1). Co-expression of these chimeras supported large GABA currents with limited desensitization, comparable to the profile for wild-type $\rho 1$ (Fig. 1a, see Table 1 for all time constants and extents of desensitiszation data and Supplementary Table 1 for GABA current amplitudes), thereby locating the main determinants of desensitization to the transmembrane and/or intracellular regions of the receptor.

Our primary measure of desensitization involved monitoring the decline of currents activated by maximal saturating concentrations of GABA. To ensure that the mutations did not adversely perturb the general structure, function or long-term trafficking of the receptor, we monitored both the dose-response curves and the recovery phase of the currents from desensitization for selected mutants. Overall, the concentration-response curves and $\mathrm{EC}_{50}$ values were minimally affected by the mutations, though certain GABA receptor constructs did generate slightly lower $\mathrm{EC}_{50}$ values, in accord with an increase in affinity that is often associated with desensitized receptors (Supplementary Fig. 2). Recoveries of the maximal peak GABA currents following desensitization were also similar for wild-type and singly mutated receptors, with complete recovery from maximal desensitization always achieved in mins (Supplementary Fig. 3). In addition, we have reported both the rates and extent of desensitization for all mutants to gain an overall view of the desensitization process (Table 1).

Internal end of M3 and M1-M2 linker control desensitization. We refined our search using homomeric $\rho 1$ receptors and sequentially replacing individual transmembrane segments, M1 to M3, with those from $\alpha 1$. These constructs yielded very small currents, precluding analysis; however, one chimera incorporating the intracellular end of M3, the M3-M4 intracellular linker and M4 of $\alpha 1$ into the $\rho 1$ subunit $\left(\rho 1^{\Delta 346}-\alpha 1\right)$, produced robust currents, which strongly desensitized (\%Des $=94 \%$ and $\tau_{\mathrm{W}}=200 \mathrm{~ms}$, Fig. 1b).

Surprisingly, incorporating just M4 from the $\alpha 1$ subunit did not affect the desensitizing phenotype of $\rho 1\left(\rho 1^{\Delta 433}-\alpha 1\right.$, Fig. 1b). We therefore targeted M3 in $\rho 1$ and replaced six contiguous residues at the carboxyl-terminal (C-terminal; intracellular) end of M3 with the homologous residues from $\alpha 1$. This produced a receptor $\left(\rho 1^{\alpha 1(\Delta 6-\text { postM3)})}\right.$ that desensitized profoundly within one second following activation by GABA (Fig. 1b). Within this six amino-acid cassette, substituting just one residue, $\rho 1^{\mathrm{T} 349 \mathrm{~K}}$, was sufficient to confer a rapid desensitizing profile on $\rho 1$ receptors (Fig. 1b).

Interestingly, on the $\rho 1^{\alpha 1(\Delta 6-\text { postM3) }}$ background, incorporating the M1-M2 intracellular linker from the $\beta 2$ subunit considerably reduced desensitization towards that for wild-type

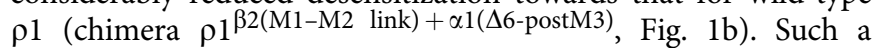
reversion was not observed after incorporating the $\alpha 1$ M1-M2 linker (Supplementary Fig. 4). These data indicate that the intracellular end of M3 and the M1-M2 linker of $\beta 2$ modulate desensitization, conceivably via an intersubunit $(\alpha-\beta)$ interaction, which is consistent with the close proximity of $\alpha 1 \mathrm{M} 3 \mathrm{C}$-terminal end to the M1-M2 linker of an adjacent $\beta 2$ subunit, as seen in our structural models (see below).

We subsequently examined this potential interaction in $\alpha 1 \beta 2$ $\mathrm{GABA}_{\mathrm{A}} \mathrm{Rs}$ by first introducing the M1-M2 linker of $\rho 1$ into $\beta 2$ subunits $\left(\beta 2^{\rho 1(\mathrm{M} 1-\mathrm{M} 2 \text { link)})}\right.$. Co-expressing this chimera with wild-type $\alpha 1$ produced receptors that, unexpectedly, desensitized almost completely at a rate 50 -fold faster than wild-type $\alpha 1 \beta 2$ receptors (Fig. 1c). Moreover, exchanging eight residues from the intracellular end of $\mathrm{M} 3$ in $\alpha 1$ and $\beta 2$ with those from $\rho 1$ resulted in a modest three-fold increase in the desensitization rate for $\alpha 1^{\rho 1(\Delta 8 \text {-postM3) }} \beta 2^{\rho 1(\Delta 8 \text {-postM3) }}$ (Fig. 1c). However, on this background, reintroducing the $\mathrm{M} 1-\mathrm{M} 2$ linker of $\rho 1$ into $\beta 2$ 


\section{Table 1 | Weighted decay time constant for desensitization $\left(\tau_{W}\right)$ and extent of desensitization (\% Des) of wild-type and mutant} $\mathrm{GABA}_{\mathrm{A}}$ and glycine receptor constructs.

\begin{tabular}{|c|c|c|c|c|c|c|c|}
\hline Construct & $\tau_{\mathbf{w}}(\mathbf{s})$ & $\%$ Des & $n$ & Construct & $\tau_{\mathbf{w}}(\mathbf{s})$ & $\%$ Des & 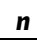 \\
\hline$\alpha 1 \beta 2$ wt & $17.4 \pm 3.6$ & $86.4 \pm 2.6$ & 17 & $\alpha 1^{\mathrm{V} 2511} \beta 2^{\mathrm{S} 247 \mathrm{I}}$ & $2.5 \pm 0.8$ & $97.5 \pm 0.8$ & 5 \\
\hline \multirow[t]{2}{*}{$\rho 1 w t$} & $23.3 \pm 7.9$ & $19 \pm 13$ & 13 & $\alpha 1^{\mathrm{V} 251 \mathrm{D}} \beta 2^{\mathrm{S} 247 \mathrm{D}}$ & $1.3 \pm 0.4$ & $93.5 \pm 1.2$ & 4 \\
\hline & & & & $\alpha 1^{\mathrm{V} 251 \mathrm{~F}} \beta 2$ & $0.78 \pm 0.20$ & $99.0 \pm 0.4$ & 6 \\
\hline$\rho 1^{\Delta 260}-\alpha 1$ & $8.1 \pm 0.5$ & $90.7 \pm 0.5$ & 3 & $\alpha 1 \beta 2^{\mathrm{S} 247 \mathrm{~F}}$ & $0.75 \pm 0.06$ & $97.4 \pm 0.5$ & 5 \\
\hline$\rho 1^{\Delta 346_{-\alpha 1}}$ & $0.20 \pm 0.04$ & $93.6 \pm 2.4$ & 6 & $\alpha 1^{\mathrm{N} 307 \mathrm{Q}} \beta 2^{\mathrm{N} 303 \mathrm{Q}}$ & $11.4 \pm 1.0$ & $90.8 \pm 0.4$ & 4 \\
\hline$\rho 1^{\Delta 433}-\alpha 1$ & $28.2 \pm 2.6$ & $11 \pm 4$ & 3 & $\alpha 1^{\mathrm{N} 307 \mathrm{~S}} \beta 2^{\mathrm{N} 303 \mathrm{~S}}$ & $1.2 \pm 0.4$ & $97 \pm 0.9$ & 4 \\
\hline$\rho 1 \alpha^{1(\Delta 6 \text {-postM3) }}$ & $1.0 \pm 0.4$ & $72.2 \pm 4.2$ & 9 & $\alpha 1^{\mathrm{N} 307 \mathrm{~V}_{\beta 2} \mathrm{N303V}}$ & $0.19 \pm 0.03$ & $99.6 \pm 0.1$ & 7 \\
\hline$\rho 1^{\text {T349K }}$ & $5.0 \pm 3.7$ & $58.6 \pm 8.0$ & 9 & $\alpha 1^{\mathrm{N} 307 \mathrm{D}} \beta 2$ & $4.4 \pm 0.1$ & $97.9 \pm 0.4$ & 4 \\
\hline$\rho 1^{\beta 2(M 1-M 2 \text { link })+\alpha 1(\Delta 6 \text {-postM3) }}$ & $10.5 \pm 3.3$ & $25.3 \pm 8.6$ & 10 & $\alpha 1 \beta 2^{\mathrm{N} 303 \mathrm{D}}$ & $0.41 \pm 0.12$ & $87.1 \pm 4.1$ & 4 \\
\hline$\alpha 1^{\mathrm{EXT}}-\rho 1^{\mathrm{TM}+\mathrm{INT}}$ & $22.9 \pm 4.0$ & $24.3 \pm 10.9$ & 4 & $\alpha 1 \beta 2 \gamma 2 \mathrm{~L}$ wt & $15.5 \pm 3.2$ & $79.8 \pm 4.5$ & 8 \\
\hline \multicolumn{8}{|l|}{$\beta 2^{\mathrm{EXT}}-\rho 1^{\mathrm{T} M}+\mathrm{INT}$} \\
\hline$\alpha 1 \beta 2^{\rho 1(M 1-M 2 ~ l i n k)}$ & $0.33 \pm 0.11$ & $98.9 \pm 0.2$ & 11 & $\alpha 1 \beta 2 \gamma 2 L^{\vee} 262 F$ & $1.3 \pm 0.2$ & $98.7 \pm 0.2$ & 7 \\
\hline$\alpha 1^{(\Delta 8 \text {-postM3) }} \beta 2^{\rho 1(\Delta 8 \text {-postM3) }}$ & $5.8 \pm 1.3$ & $96.1 \pm 1.1$ & 6 & $\alpha 1 \beta 2 \gamma 2 \mathrm{~L}^{\mathrm{H} 318 \mathrm{~V}}$ & $2.2 \pm 0.3$ & $96.3 \pm 0.5$ & 5 \\
\hline$\alpha 1^{(\Delta 8-\text { postM3) }}$ & $4.6 \pm 1.5$ & $80.4 \pm 6.2$ & 7 & GlyR $\alpha 1$ wt & $10.7 \pm 3.4$ & $72.4 \pm 8.1$ & 12 \\
\hline \multicolumn{8}{|l|}{$\beta 2^{\rho 1(\mathrm{M} 1-\mathrm{M} 2 \text { link }+\Delta 8 \text {-postM3) }}$} \\
\hline$\alpha 1^{\rho 1 M 3} \beta 2^{\rho 1} M 3$ & $17.4 \pm 6.1$ & $33.7 \pm 10.8$ & 6 & GlyR $\alpha 1^{\rho 1(\Delta 6-p o s t M 3)}$ & $0.88 \pm 0.23$ & $98.2 \pm 1.0$ & 6 \\
\hline$\alpha 1^{\mathrm{L300V}} \beta 2^{\mathrm{L} 296 \mathrm{~V}}$ & $26.7 \pm 12.7$ & $25.6 \pm 5.8$ & 11 & GlyR $\alpha 1^{L 298 V}$ & $17.2 \pm 6.7$ & $64.8 \pm 6.2$ & 3 \\
\hline$\alpha 1^{\mathrm{G} 258 \mathrm{~A}} \beta 2^{\mathrm{G} 254 \mathrm{~A}}$ & $4.9 \pm 1.4$ & $93.5 \pm 1.5$ & 12 & GlyR $\alpha 1^{\mathrm{G} 256 \mathrm{~V}}$ & $0.84 \pm 0.16$ & $99.6 \pm 0.3$ & 9 \\
\hline$\alpha 1^{\mathrm{G} 258 V}{ }_{\beta 2}^{\mathrm{G} 254 \mathrm{~V}}$ & $1.3 \pm 0.6$ & $93.3 \pm 1.2$ & 8 & GlyR $\alpha 1^{\mathrm{V} 294 \mathrm{~L}}$ & $17.1 \pm 6.0$ & $14.8 \pm 8.1$ & 7 \\
\hline$\alpha 1^{\mathrm{V} 296 \mathrm{~L}} \beta 2^{\mathrm{V} 292 \mathrm{~L}}$ & $93 \pm 15$ & $30.4 \pm 3.3$ & 5 & GlyR $\alpha 1^{A 249 F}$ & $0.85 \pm 0.65$ & $98.0 \pm 0.9$ & 4 \\
\hline$\alpha 1^{\mathrm{V} 251 \mathrm{~A}} \beta 2^{\mathrm{S} 247 \mathrm{~A}}$ & $2.5 \pm 0.5$ & $96.8 \pm 0.6$ & 5 & GlyR $\alpha 1^{N 305 V}$ & $0.18 \pm 0.05$ & $98.5 \pm 1.6$ & 5 \\
\hline
\end{tabular}

$\left(\alpha 1^{\rho 1(\Delta 8-\text { postM3) }} \beta 2^{\rho 1(\mathrm{M} 1-\mathrm{M} 2 \text { link }+\Delta 8 \text {-postM3) }}\right.$, produced relatively little effect on desensitization compared with the wild-type receptor (Fig. 1c). If the combined effect of these two modifications had been additive, we would have expected the double chimera to desensitize even faster than the $\alpha 1 \beta 2^{\rho 1(\mathrm{M} 1-\mathrm{M} 2}$ link) receptors. Therefore, the non-additive nature of these mutations further supports an interaction between the intracellular end of M3 and the M1-M2 linker, which could represent a cassette of complementary residues conferring desensitizing properties on the GABA ion channel.

$M 2$ and M3 interface strongly affects $\mathrm{GABA}_{\mathrm{A}} \mathrm{R}$ desensitization. While the identified cassette critically modulates desensitization, it is not the sole determinant. Indeed, exchanging the entire transmembrane portion of $\mathrm{M} 3$ for $\alpha 1$ and $\beta 2$ with $\rho 1$, virtually eliminated desensitization when these two chimeric subunits were co-expressed ( $\alpha 1^{\rho 1 \mathrm{M} 3} \beta 2^{\rho 1 \mathrm{M} 3}$, Supplementary Fig. 5). We therefore compared the primary sequences for $M 3$, and noted that the residue homologous to V338 in $\rho 1$ is a conserved leucine in other $\mathrm{GABA}_{\mathrm{A}} \mathrm{R}$ and GlyR subunits (Supplementary Fig. 6). By substituting these leucines for valines $\left(\alpha 1^{\mathrm{L} 300 \mathrm{~V}} \beta 2^{\mathrm{L} 290 \mathrm{~V}}\right)$, we created receptors that displayed very little desensitization (Fig. 2a). Notably, this was achieved with very little change in the GABA concentration-response curve for $\alpha 1^{\mathrm{L} 300 \mathrm{~V}} \beta 2^{\mathrm{L} 296 \mathrm{~V}}$ compared with that for wild-type receptors (Fig. 3), indicating the gating efficacy was minimally affected.

To understand how $\mathrm{M} 3$ residues could affect receptor function, we constructed a three-dimensional (3D) model of the $\alpha 1 \beta 2$ $\mathrm{GABA}_{\mathrm{A}} \mathrm{R}$ (Fig. 2a) based on the structure of the C. elegans glutamate-gated $\mathrm{Cl}^{-}$channel $(\mathrm{GluCl})$ in the open conformation $^{14}$, which shares high sequence homology with $\mathrm{GABA}_{\mathrm{A}} \mathrm{Rs}$ and GlyRs (Supplementary Fig. 6). In this model, the side chain of the M3 leucine $\left(\alpha 1^{\mathrm{L} 300}\right)$ is orientated towards M2 near the $4^{\prime}$ position (Fig. 2b,c; Supplementary Fig. 7), and therefore any conformational changes to M3 may be detected in M2 by a proximal glycine residue $\left(\alpha 1^{\mathrm{G} 258}\right)$ that is highly conserved in all $\mathrm{GABA}_{\mathrm{A}} \mathrm{R}$ and GlyR subunits (Supplementary Fig. 6).
Replacing this conserved glycine with neutral alanine in $\alpha 1$ and the $\beta 2$ subunits $\left(\alpha 1^{\mathrm{G} 258 \mathrm{~A}} \beta 2^{\mathrm{G} 254 \mathrm{~A}}\right)$ produced receptors that desensitized 2.5-fold faster than the wild type, while mutation to bulky hydrophobic valines $\left(\alpha 1^{\mathrm{G} 258 \mathrm{~V}} \beta 2^{\mathrm{G} 254 \mathrm{~V}}\right)$ increased the desensitization rate by 14 -fold (Fig. 2a) without changing the GABA concentration-response curve (Fig. 3).

We next assessed the importance of the highly conserved M3 valine $\left(\alpha 1^{\mathrm{V} 296}\right)$, which is located one $\alpha$-helical turn above $\alpha 1^{\mathrm{L} 300}$ (Supplementary Fig. 6). Together these residues effectively straddle the $4^{\prime}$ glycine (G258) in M2 (Fig. 2b). Significantly, their mutation to leucines in $\alpha 1^{\mathrm{V} 296 \mathrm{~L}} \beta 2^{\mathrm{V} 292 \mathrm{~L}}$ strongly disrupted desensitization, further suggesting that rearrangements to the lower part of the M2/M3 intrasubunit interface underlies the process of receptor desensitization (Fig. 2b).

Exploring this interface further, we examined the consequences of mutating $\alpha 1^{\mathrm{V} 251}$ and $\alpha 1^{\mathrm{N} 307}$. Valine 251 is located at the $-3^{\prime}$ position intracellular to $\mathrm{M} 2$, bordering the M1-M2 linker, and facing M3 at the level of $\alpha 1^{\mathrm{N} 307}$ (Fig. 2b,c). Mutating $\alpha 1^{\mathrm{V} 251}$ and the homologous $\beta 2^{\mathrm{S} 247}$ to isoleucines (Fig. 2b), alanines or aspartates (Table 1), produced a 7 - to 14 -fold increase in the rate of desensitization, while phenylalanine mutants $\left(\alpha 1^{\mathrm{V} 251 \mathrm{~F}} \beta 2^{\mathrm{S} 247 \mathrm{~F}}\right)$ did not yield a resolvable current; however, the co-expression with their wild-type counterparts $\left(\alpha 1^{\mathrm{V} 251 \mathrm{~F}} \beta 2\right.$ and $\left.\alpha 1 \beta 2^{\mathrm{S} 247 \mathrm{~F}}\right)$ created receptors desensitizing more than 20 -fold faster than wild-type $\alpha 1 \beta 2$ counterparts (Fig. 2b, Table 1). It is possible that the double mutant receptors are functional but may desensitize too rapidly to be resolved. Indeed, we used excised patch recordings (see Methods) but still failed to resolve any current, which may reflect a desensitization rate that is faster than the rate of ion channel opening.

Similar results were obtained with the adjacent residue $\alpha 1^{\mathrm{N} 307}$ and the homologous $\beta 2^{\mathrm{N} 303}$. Conservatively exchanging these asparagines for glutamines did not affect receptor function, while $\alpha 1^{\mathrm{N} 30 \mathrm{~S}_{3}} \beta 2^{\mathrm{N} 303 \mathrm{~S}}$ and $\alpha 1^{\mathrm{N} 307 \mathrm{~V}} \beta 2^{\mathrm{N} 303 \mathrm{~V}}$ receptors desensitized 15 and 100-fold faster, respectively, compared with wild-type $\alpha 1 \beta 2$ (Fig. 2c, Table 1). Co-expression of $\alpha 1^{\mathrm{N} 307 \mathrm{D}}$ and $\beta 2^{\mathrm{N} 303 \mathrm{D}}$ failed to elicit current, but co-expression with their respective wild-type subunits revealed 4- to 40 -fold increases in desensitization 
a
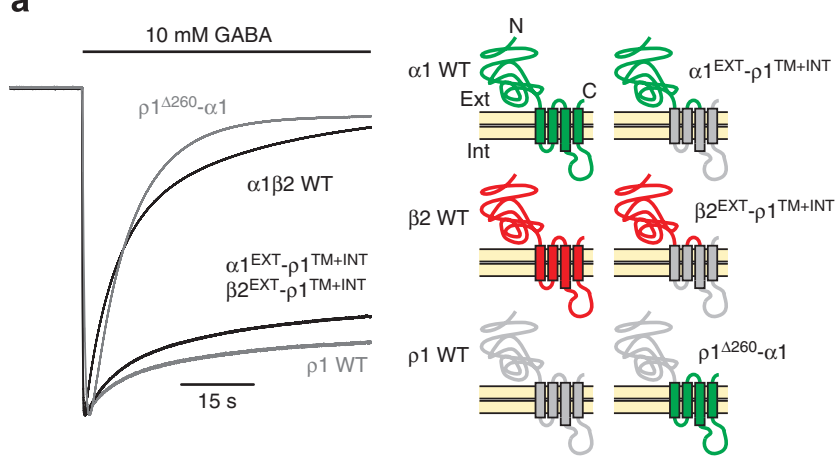

b

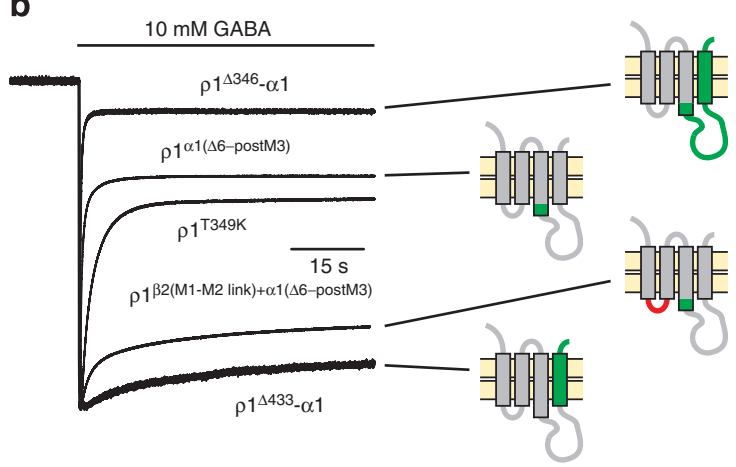

C

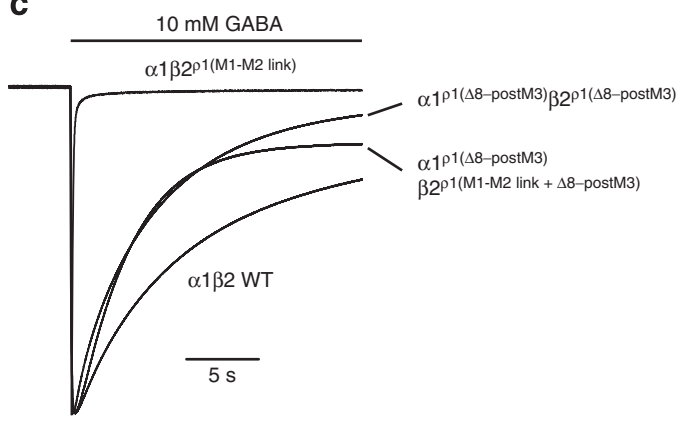

Figure 1 | Intracellular end of M3 and the M1-M2 linker control desensitization of $\mathbf{G A B A}_{\mathbf{A}} \mathbf{R s}$. (a-c) Peak-scaled membrane currents elicited by $10 \mathrm{mM} \mathrm{GABA}$ (black line), showing the desensitization phase for the indicated receptor constructs (left column). The recovery phase is omitted for clarity. See Table 1 for values of $\tau_{\mathrm{w}}$ and extent of desensitization (\% Des) in all figures. The subunit chimeras are depicted by a colour code: green $(\alpha 1)$, red ( $\beta 2)$ and grey ( $\rho 1)$ (right column). Numbering refers to the position of the interface between the two subunits in the chimera. $\mathrm{TM} / \mathrm{M}$, transmembrane domain, INT, intracellular loops.

kinetics (Table 1). The lack of current, apparent with these double mutants, could thus be due to their profoundly enhanced rate of desensitization. Overall these results are in complete accord with residues located at the M2/M3 interface in the lower part of the membrane, playing a key role in receptor desensitization.

To investigate the importance of some of the key residues at the M2-M3 interface, and to ensure that the use of Xenopus oocytes was not altering the desensitizing profiles of the GABA-activated currents, we explored the impact of several receptor mutants when expressed in HEK cells. As observed with the oocyte-based experiments, the expression of $\alpha 1^{\mathrm{V} 251 \mathrm{~F}} \beta 2$ generated currents that desensitized faster, by $\sim 10$-fold compared with those for the $\alpha 1 \beta 2$ wild type (Supplementary Fig. 8, Supplementary Table 3). Again, similar current profiles were evident by co-expressing the nearby residue, $\alpha 1^{\mathrm{N} 307 \mathrm{~V}}$ with the homologous $\beta 2^{\mathrm{N} 303 \mathrm{~V}}$, in HEK cells giving a sevenfold increase in the desensitization rate (Supplementary Fig. 8, Supplementary Table 3). a
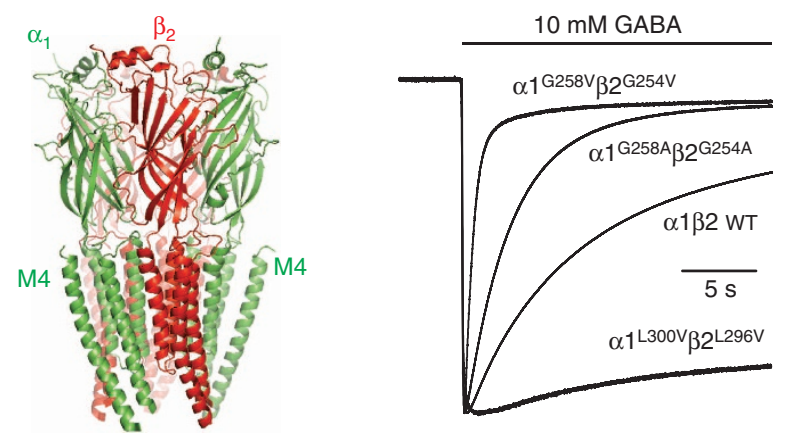

b
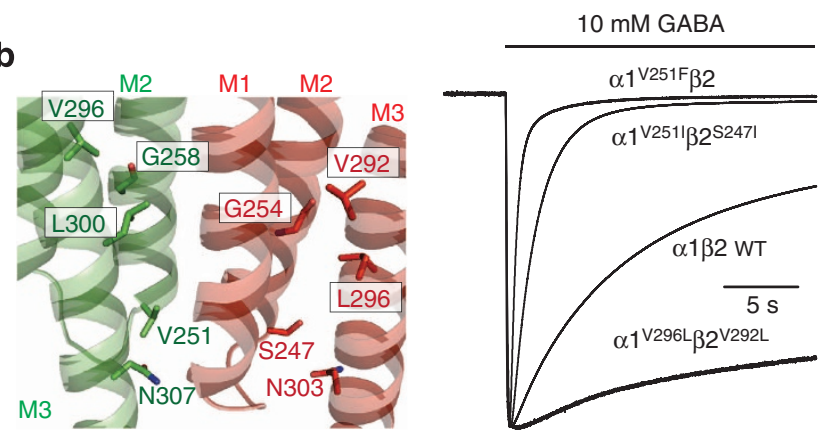

c
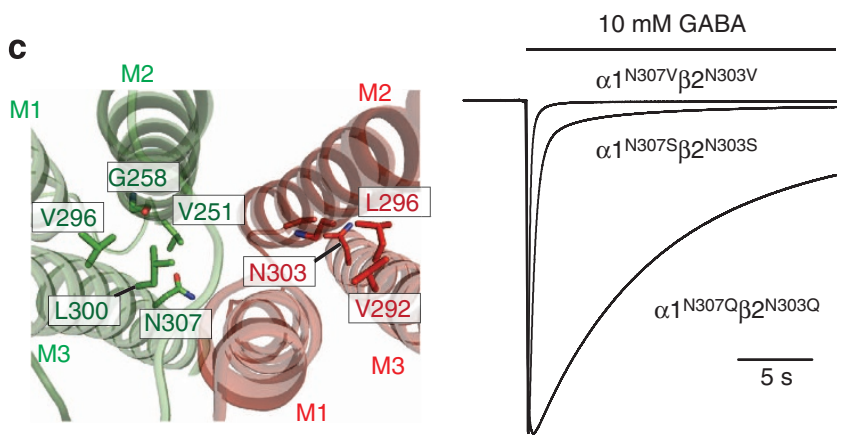

Figure 2 | Mutating the intracellular end of the M2/M3 interface regulates desensitization of $\alpha \mathbf{1 \beta 2} \mathbf{G A B A} \mathbf{A}_{\mathbf{A}}$ Rs. (a) Left: $3 \mathrm{D}$ model of an $\alpha 1 \beta 2$ $\mathrm{GABA}_{\mathrm{A}} \mathrm{R}$ based on $\mathrm{GluCl}$ template. Right in a-c: membrane currents induced by $10 \mathrm{mM}$ GABA. (b) Left: enlarged side view of the intracellular end of the ion channel showing transmembrane domains M1-M3 for $\alpha 1$ (green) and $\beta 2$ (red) subunits and the positions of various labelled residues. (c) Left: enlarged plan view of the ion channel. Note, in $\mathbf{b}, \mathbf{c}, \mathrm{M} 4$ segments were omitted for clarity.

$\gamma 2$ subunit $\mathrm{M} 2$ and $\mathrm{M} 3$ affects $\alpha 1 \beta 2 \gamma 2 \mathrm{GABA}_{\mathrm{A}} \mathrm{R}$ desensitization. To initially simplify our structural approach to exploring desensitization, we used $\alpha 1 \beta 2 \quad G_{A B A_{A}} R$ s. However, native synaptic $\mathrm{GABA}_{\mathrm{A}}$ receptors will contain a single copy of the $\gamma 2$ subunit $^{15}$. To probe desensitization in the $\alpha \beta \gamma$ receptor, we examined the effect of mutations at the intracellular end of the $\gamma 2$ subunit. We selected $\gamma 2^{\mathrm{V} 262}$ and $\gamma 2^{\mathrm{H} 318}$ for mutation since these are homologous to $\alpha 1^{\mathrm{V} 251}$ and $\alpha 1^{\mathrm{N} 307}$, respectively, which have a profound effect on desensitization of $\alpha \beta$ receptors (Supplementary Fig. 6). While coexpressing wild-type $\alpha 1, \beta 2$ and $\gamma 2 \mathrm{~L}$ subunits produced receptors that desensitized similarly (\% Des $=80 \%, \tau_{\mathrm{W}}=15.5 \mathrm{~s}$ ) to wild-type $\alpha 1 \beta 2$, mutating $\gamma 2 \mathrm{~L}^{\mathrm{V} 262 \mathrm{~F}}$ and $\gamma 2 \mathrm{~L}^{\mathrm{H} 318 \mathrm{~V}}$ increased the rate of desensitization by 12 - and 7 -fold respectively, and strongly increased the extent of desensitization (\% Des $=98.7$ and 96.3, respectively; Fig. 4a). These mutations did not generally perturb receptor function as GABA potency was minimally affected at $\alpha 1 \beta 2 \gamma 2 \mathrm{~L}^{\mathrm{V} 262 \mathrm{~F}}$ and $\alpha 1 \beta 2 \gamma 2 \mathrm{~L}^{\mathrm{H} 318 \mathrm{~V}}$ compared with wild-type $\alpha 1 \beta 2 \gamma 2 \mathrm{~L} \mathrm{GABA}_{\mathrm{A}} \mathrm{Rs}$ (Supplementary Fig. 9), suggesting that receptor gating was unaffected. Moreover, we also examined 
another key pharmacological facet of $\gamma 2$-containing $\mathrm{GABA}_{\mathrm{A}} \mathrm{Rs}$ involving modulation by benzodiazepines ${ }^{16}$. Diazepam-induced potentiation of low concentration $\left(\mathrm{EC}_{1-2}, 1-3 \mu \mathrm{M}\right) \mathrm{GABA}$ currents at wild-type $\alpha 1 \beta 2 \gamma 2 \mathrm{~L}$, and mutant $\alpha 1 \beta 2 \gamma 2 \mathrm{~L}^{\mathrm{V} 262 \mathrm{~F}}$ and $\alpha 1 \beta 2 \gamma 2 \mathrm{~L}^{\mathrm{H} 318 \mathrm{~V}}$ receptors, remained unaltered $(2.53 \pm 0.20$-fold $(\alpha 1 \beta 2 \gamma 2 \mathrm{~L}) ; 2.14 \pm 0.16$-fold $\left(\alpha 1 \beta 2 \gamma 2 \mathrm{~L}^{\mathrm{V} 262 \mathrm{~F}}\right)$; and $2.51 \pm 0.05$-fold $\left.\left(\alpha 1 \beta 2 \gamma 2 \mathrm{~L}^{\mathrm{H} 318 \mathrm{~V}}\right), n=3\right)$, again suggesting that the mutations have neither affected gating, nor assembly, nor the folding of the receptors. It is important to note that, since there is only one copy of the $\gamma 2$ subunit per $\alpha 1 \beta 2 \gamma 2$ receptor pentamer, there is also only one copy of the $\gamma 2$ subunit mutation, further emphasizing the importance of the cytoplasmic end of the M2/M3 interface on the desensitization of Cys-loop receptors.

A similar mechanism accounts for the desensitization of GlyRs. If the identified residues in $\mathrm{GABA}_{\mathrm{A}} \mathrm{Rs}$ form a part of the generic mechanism for receptor desensitization at inhibitory Cys-loop receptors, then we should be able to replicate the effects in GlyRs. Applying saturating concentrations $(10 \mathrm{mM})$ of glycine to GlyR $\alpha 1$ homomeric receptors (GlyR $\alpha 1)$ evoked peak currents that desensitized by $\sim 72 \%$ with a $\tau_{\mathrm{w}}$ of $11 \mathrm{~s}$ (Table 1 , Fig. $4 \mathrm{~b}, \mathrm{c}$ ). As mutations to the M1-M2 linker of GlyR $\alpha 1$ have been reported to strongly affect desensitization ${ }^{17}$, we focused on the intracellular end of $M 3$, as we had done with the $G_{A B A} R$, and exchanged six consecutive residues with those from $\rho 1$. This chimera $\left(\right.$ GlyR $\left.\alpha 1^{\rho 1(\Delta 6 \text {-postM3) }}\right)$ desensitized by $\sim 98 \%\left(\tau_{\mathrm{w}}=0.9\right.$ s, Fig. $\left.4 \mathrm{~b}\right)$, establishing the intracellular end of M3 in GlyRs as a key component for desensitization.

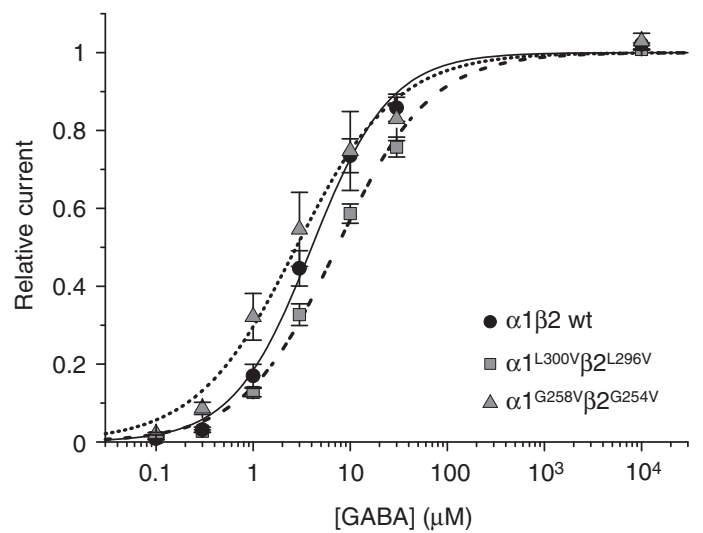

Figure 3 | Effects of mutations $\alpha \mathbf{1}^{\mathrm{L30OV}_{\beta 2}}{ }^{\mathrm{L296V}}$ and $\alpha 1^{\mathrm{G} 258 \mathrm{~V}} \beta 2^{\mathrm{G} 254 \mathrm{~V}}$ on GABA sensitivity. GABA concentration-response curves for wild-type (wt) $\alpha 1 \beta 2\left(\mathrm{EC}_{50}=4.1 \pm 0.7 \mu \mathrm{M}, n_{\mathrm{H}}=1.08 \pm 0.07, n=6\right), \alpha 1^{\mathrm{L300V}} \beta 2^{\mathrm{L} 296 \mathrm{~V}}$ $\left(\mathrm{EC}_{50}=7.3 \pm 0.9 \mu \mathrm{M}, n_{\mathrm{H}}=0.91 \pm 0.02, n=5\right)$ and $\alpha 1^{\mathrm{G} 258 \mathrm{~V}} \beta 2^{\mathrm{G} 254 \mathrm{~V}}$ receptors $\left(E C_{50}=3.0 \pm 0.9 \mu \mathrm{M}, n_{H}=0.89 \pm 0.19, n=5\right)$. Error bars are s.d.
We then examined the effect of single mutations towards the cytoplasmic end of M2 and M3. GlyR $\alpha 1^{\mathrm{L} 298}$ is the homologous $\mathrm{M} 3$ leucine to $\mathrm{GABA}_{\mathrm{A}} \mathrm{R} \alpha 1^{\mathrm{L} 300}$. Although the mutant GlyR$\alpha 1^{\mathrm{L} 298 \mathrm{~V}}$ did not affect desensitization (Table 1), mutating the highly conserved M2 glycine in GlyR $\alpha 1^{\mathrm{G} 256 \mathrm{~V}}$, significantly increased desensitization ( $\%$ Des $=99.4 \%, \tau_{\mathrm{W}}=0.8 \mathrm{~s}$, Fig. $4 \mathrm{c}$ ) while minimally affecting the apparent affinity for glycine (Supplementary Fig. 2b). Furthermore, mutating the M3 V294

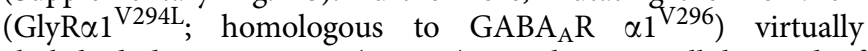
abolished desensitization (Fig. 4c). At the intracellular end of $\mathrm{M} 2$ and $\mathrm{M} 3$, we then targeted GlyR $\alpha 1^{\mathrm{A} 249}$ (M2) and GlyR $\alpha 1^{\mathrm{N} 305}$ (M3), which are homologous to GABA $\mathrm{R} \alpha 1^{\mathrm{V} 251}$ and $\alpha 1^{\mathrm{N} 307}$. In accord with our $\mathrm{GABA}_{\mathrm{A}} \mathrm{R}$ data, the mutant GlyR $\alpha 1^{\mathrm{A} 249 \mathrm{~F}}$ and GlyR $\alpha 1^{\mathrm{N} 305 \mathrm{~V}}$ displayed near-complete desensitization with rates 13- and 60-fold higher, respectively, than wild-type GlyR $\alpha 1$ (Fig. 4b). This is consistent with our results for $\alpha 1 \beta 2 \mathrm{GABA}_{\mathrm{A}} \mathrm{Rs}$, and indicates that similar determinants and therefore mechanisms of desensitization apply to both $\mathrm{GABA}_{\mathrm{A}} \mathrm{Rs}$ and GlyRs, involving structural rearrangements at the cytoplasmic end of the M2/M3 interface.

Locating the desensitization gate using a channel blocker. To understand how the identified residues regulate the desensitization in $\mathrm{GABA}_{\mathrm{A}} \mathrm{Rs}$ and GlyRs, we compared the crystal structure of GluCl, with those of ELIC and GLIC, the prokaryotic homologues of Cys-loop receptors in putative shut and open conformations, respectively ${ }^{18-20}$. While receptor activation involves an increase of the pore diameter between the $9^{\prime}$ and $20^{\prime}$ positions, there is a corresponding constriction of the pore at its cytoplasmic end, between $-3^{\prime}$ and $4^{\prime}$ (Fig. 5a) ${ }^{14,18}$. We hypothesized that desensitization could be an extension of the conformational rearrangements that occur during the activation process, which is consistent with desensitization proceeding from the open state of the channel ${ }^{21,22}$. This implies that desensitization would involve a gate that is located proximal to the cytoplasmic end of the channel.

To corroborate our desensitization gate model for inhibitory Cys-loop receptors, we used the pore blocker, picrotoxin (PTX), since its binding site is generally considered to be located deep in the pore (between $-2^{\prime}$ and $2^{\prime}$ ) precisely where the pore constricts during the activation process (Fig. 5a) ${ }^{14,23}$. After applying a low GABA concentration $(0.3 \mu \mathrm{M})$ to $\alpha 1 \beta 2$ receptors, enabling the resting (shut) state(s) of the receptor to remain significantly populated, we co-applied a saturating concentration $(50 \mu \mathrm{M})$ of PTX, which blocked the GABA current. Subsequent washout of PTX while still in GABA revealed an extremely slow dissociation of the pore blocker (Fig. 5b), consistent with it being trapped in a resting (shut) state of the channel ${ }^{23}$. Repeating this protocol now with a saturating GABA concentration $(10 \mathrm{mM})$ to deliberately a

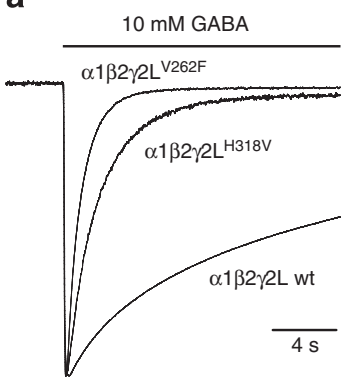

b

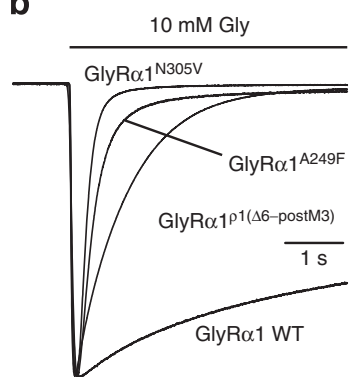

C

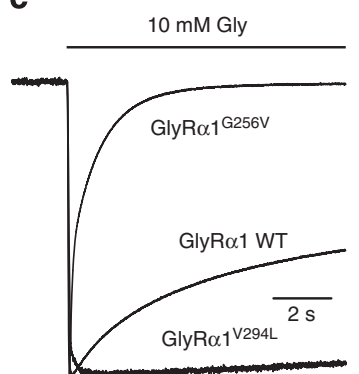

Figure 4 | Residues affecting desensitization in heteromeric $\alpha \mathbf{1} 12 \gamma \mathbf{2} \mathbf{G A B A}_{\mathbf{A}}$ receptors and homomeric GlyR $\alpha \mathbf{1}$ glycine receptors. (a) Membrane currents activated by $10 \mathrm{mM}$ GABA showing desensitization of $\gamma 2$ subunit-containing wild-type and mutant $\mathrm{GABA}_{\mathrm{A}}$ receptors. (b,c) Membrane currents activated by $10 \mathrm{mM}$ glycine, showing desensitization of glycine receptors, both wild type and mutants (see text for details). 
a

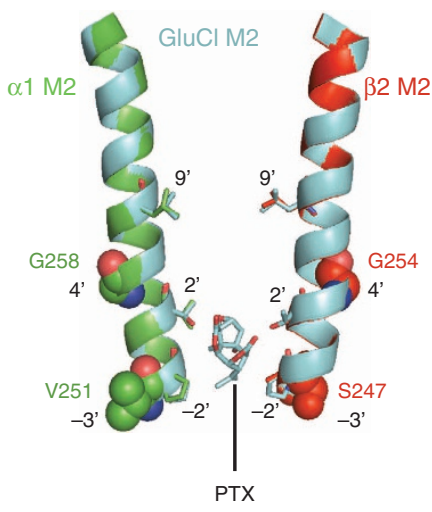

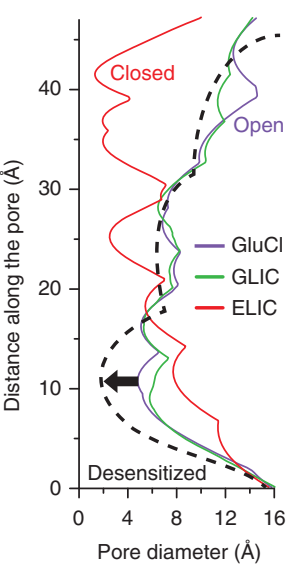

b

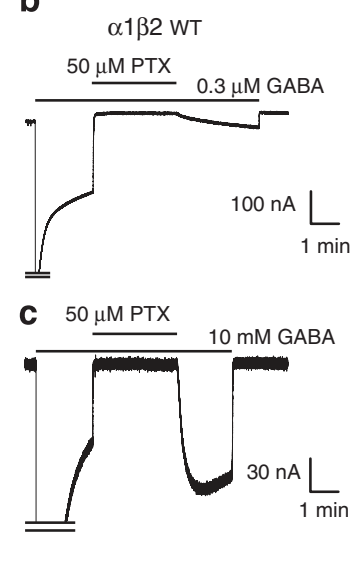

Figure 5 | Promoting desensitization of $\mathbf{G A B A}_{\mathbf{A}}$ Rs causes fast dissociation of the pore blocker PTX. (a) Left: side-view cutaway section through the transmembrane domains showing two ( $\alpha 1$-green, $\beta 2$-red) of the five $M 2$ helices from our $\alpha 1 \beta 2 G A B A_{A} R$ model overlaid with the $M 2$ helices of the PTX-bound GluCl structure (light blue; pdb 3RI5 (ref. 14)). Note the deep location of the PTX-binding site between locations $2^{\prime}$ and $-2^{\prime}$. Right: predicted pore diameter plotted as a function of the distance along the pore axis for $\mathrm{GluCl}$, GLIC (open; pdb 3EAM (ref. 18)) and ELIC (shut; pdb 2VLO (ref. 19)). This is vertically aligned with the left panel schema for cross comparison. The dashed line reflects the hypothesis that desensitization is an extension of the activation process, leading to a desensitization gate located between positions $-3^{\prime}$ and $4^{\prime}$. (b) Representative membrane currents showing slow dissociation of PTX from $\alpha 1 \beta 2 \mathrm{GABA}_{A}$ Rs when activated by a low concentration of GABA $(0.3 \mu \mathrm{M}, n=6)$. (c) Membrane currents showing fast dissociation of PTX from $\alpha 1 \beta 2 \mathrm{GABA}_{A}$ Rs activated by saturating concentrations of GABA (10 mM, $\left.n=5\right)$. Note the peak currents are truncated for clarity.

drive receptors into the desensitized state, the apparent dissociation of PTX was much faster (Fig. 5c). This implies that PTX is not trapped in a desensitized state and that the desensitization gate must be distinct from the activation gate (Model 1, Fig. 6a).

Two simple schemes may explain the fast dissociation of PTX in the presence of saturating GABA. First, PTX binding/ unbinding could be the same to open and desensitized receptor states. However, when GABA is saturating, the peak current after washing out PTX is clearly larger than the steady-state current before its application, which is not predicted by equal binding/ unbinding to both states (Model 2, Fig. 6b). Second, PTX binding could be prevented in the desensitized state (Model 3, Fig. 6c). The recovery of current following PTX removal could then reflect two distinct processes: PTX dissociation from its binding site and subsequent receptor desensitization. For this scheme, we would expect the recovery current to exhibit a peak followed by a plateau. However, such behaviour is not obvious from our recordings with the $\mathrm{GABA}_{\mathrm{A}} \mathrm{R}$ (Fig. $5 \mathrm{c}$ ), probably because PTX dissociation is much slower than the rate of desensitization of GABA $_{\mathrm{A}}$ Rs (Fig. 6c, Supplementary Table 2).

To gain a clearer view as to where PTX is binding in relation to our proposed desensitization locus, we examined GlyRs, where PTX dissociation is notably much faster ${ }^{24,25}$. During saturating glycine concentrations, PTX blocked the plateau current (Fig. 7a). Washing out PTX now revealed a clear peak-plateau current profile as expected theoretically, indicating that PTX had blocked the receptor in an open conformation, a profile that is accurately predicted only by Model 3 (Fig. $7 \mathrm{~b}-\mathrm{d}$ ). These observations are consistent with a mechanism whereby the PTX-binding site spatially overlaps the desensitization gate. Furthermore, as desensitization leads to an increase in the agonist occupancy, such a model could account for the negative allosteric interaction between the receptor agonist and PTX ${ }^{24,25}$.

\section{Discussion}

The present view of desensitization at Cys-loop receptors is that the molecular determinants are most likely contained within the $\mathrm{ECD}^{26}$ or the ECD-TMD coupling interface ${ }^{27,28}$. Our study indicates that a different domain is involved whereby the cytoplasmic end of the ion channel forms a physical desensitization gate in inhibitory Cys-loop receptors. While this may initially appear contradictory to earlier studies, a role for residues in the ECD or the ECD-TMD interface in setting macroscopic desensitization can be entirely reconciled with our new view. First, in the event that channel opening precedes desensitization, a mutation affecting the efficacy of gating could ultimately affect the macroscopic rate of desensitization without actually modifying the microscopic rate of desensitization. Interestingly, the ECD-TMD coupling interface is critical in setting the efficacy of channel gating. Accordingly, exchanging residues in this region between $n A C h R$ and $5 \mathrm{HT}_{3} \mathrm{Rs}$ not only switches the desensitization properties of the receptors, but also their single-channel open lifetimes ${ }^{27}$.

Second, our proposal for a constriction (gate) of the channel lumen near its intracellular end during desensitization is likely to be accompanied by conformational rearrangements at the extracellular end that should be constrained by residues in the ECD-TMD coupling interface. Considering that M2 helices can exhibit rigid-body motion during gating ${ }^{12,29}$, we would predict that the pore may widen at its extracellular end during desensitization. This could be consistent with conformational rearrangements at the ECD-TMD interface of $\mathrm{GABA}_{\mathrm{A}}$ receptors during desensitization, as reported by voltage-clamp fluorometry $^{28}$. Moreover, such an effect has recently been proposed for GLIC, using electron paramagnetic resonance (EPR) spectroscopy to measure the distance between spinlabelled cysteines introduced along the ion channel pore ${ }^{30}$.

Interestingly, EPR predicts that desensitization might involve a mid-membrane gate with the intracellular end of the channel remaining mostly fixed. However, there are caveats to the interpretations of EPR data. First, in the narrowest part of the GLIC channel, spin labels might occlude the pore, thus acting as pore blockers, and as for PTX-bound GABA receptors, desensitization could conceivably be prevented by the labelling. Unfortunately, the irreversible inhibition by pore-blocking spinlabels would also render these receptors unsuitable for electrophysiological studies. Second, in the confined space of an ion channel pore, it is likely that the motion of the spin labels is also 
a

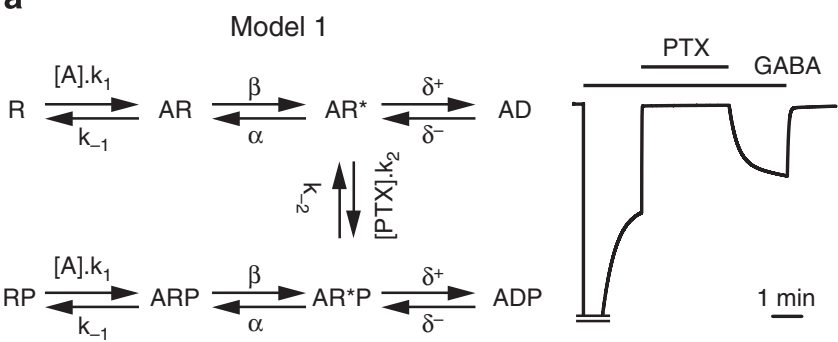

b

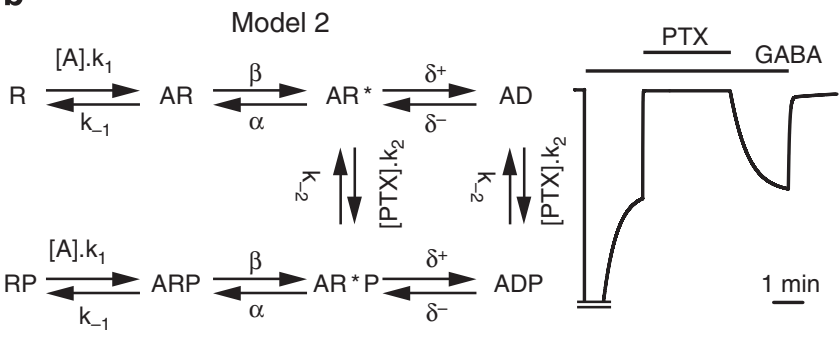

C

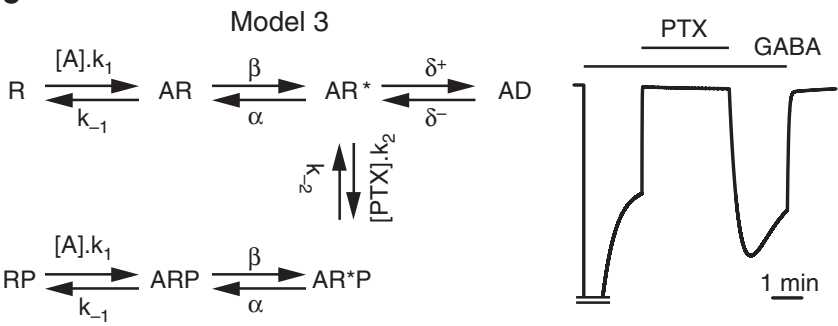

Figure 6 | Simulation of GABA currents after block by and recovery from PTX. (a-c) Left: kinetic models 1-3 used to predict the recovery of agonistinduced currents after wash-out of PTX (or P) in the presence of saturating concentrations of the agonist ( $[A] ; 10 \mathrm{mM} G A B A)$. Receptors states are: $R$ inactive, agonist-unbound receptor; $A R$ inactive, agonist-bound receptor; $\mathrm{AR}^{\star}$ agonist-bound activated receptor; $A D$ agonist-bound desensitized receptor, all with or without bound PTX. Right: predicted membrane currents, generated from the models, for wild-type $\alpha 1 \beta 2 \mathrm{GABA}_{A} \mathrm{Rs}$ activated by $10 \mathrm{mM}$ GABA in the presence and absence of $50 \mu \mathrm{M}$ PTX. See Supplementary Table 2 for the numerical values of the parameters. (a) Model 1: the PTX-blocked open receptor (AR*P) can desensitize, but PTX binding and unbinding cannot occur to or from either the resting $(R / R P, A R / A R P)$ or desensitized (AD/ADP) receptor states. (b) Model 2: PTX binding and unbinding is permitted to both open $\left(A R^{\star} / A R^{\star} P\right)$ and desensitized states. (c) Model 3: PTX binding prevents desensitization (that is, there is no ADP state). constrained. Thus, conformational changes around the spin labels could cause dynamic reorientation, making the extraction of distance information quite challenging ${ }^{31}$. For these reasons, EPR spectroscopy could be confounding when studying conformational rearrangements in the constricted space of an ion channel.

It is also important to note that a previous study showed that M1 and M2 were important in setting the desensitization properties of $\gamma 2$ and $\delta$ subunit-containing $\mathrm{GABA}_{\mathrm{A}}$ receptors ${ }^{3}$. While the molecular mechanisms were unclear, these results are interpretable in the light of our present study. The importance of M2 is clearly demonstrated by our mutagenesis data, and from our proposal regarding the location of a desensitization gate. Moreover, as there are extensive interactions between the TMDs, M1 would be expected to affect the conformation of both M2 and M3, and could also influence desensitization by affecting the M1-M2 linker. We should add a cautionary note to emphasize that perturbations to receptor structure can potentially have far reaching ramifications for predicting the consequences of mutagenesis to a functional outcome. For this reason, it is hard to predict the effects of residue substitution in the M2-M3 linker when manipulating the side-chain volume, charge and hydrophobicity. Nevertheless, structure-function studies of Cys-loop receptor activation, using similar methodologies to those employed here have proved to be very precise tools in identifying and attributing key parts of the receptor involved in function ${ }^{12,29}$, as evidenced by recent corroborating data between receptor function and the crystal structure of the apo form of $\mathrm{GluCl}^{32}$.

The molecular mechanisms underlying the desensitization of inhibitory Cys-loop receptors, which may conceivably extend to the entire Cys-loop family, appear strikingly different from the mechanisms responsible for desensitization of ionotropic GluRs. This is unsurprising, since from a structural point of view, Cys-loop receptors are quite distinct from ionotropic GluRs by forming pentamers with the ECD of each subunit interacting to form a ring, and the agonist binding sites located at interfaces between adjacent $\mathrm{ECDs}^{7,33}$. By contrast, ionotropic GluRs are tetramers harbouring discrete intrasubunit-binding sites 7,8 . Moreover, Cys-loop receptor subunits contain four transmembrane segments, which differ from the three transmembrane segments and one re-entrant P-loop topology of ionotropic GluR subunits.

The cytoplasmic end of the pore in Cys-loop receptors also contains the ion selectivity filter ${ }^{34}$. The conformational changes proposed to underlie desensitization here are reminiscent of the collapse of the selectivity filter that is considered responsible for slow inactivation of voltage-gated $\mathrm{K}^{+}$and $\mathrm{Na}^{+}$channels ${ }^{35-37}$. a

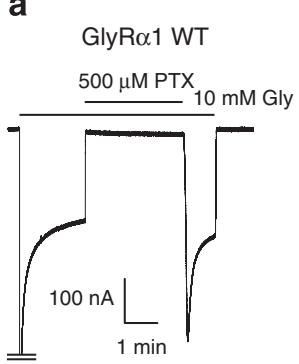

b

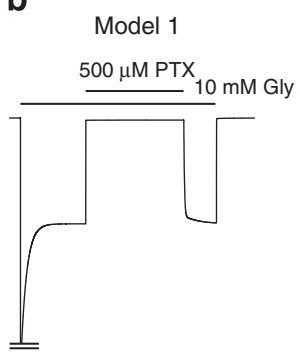

C

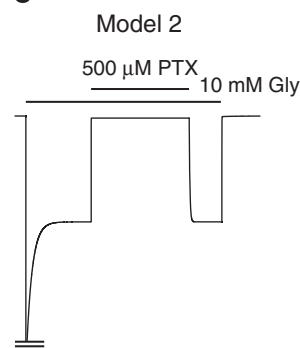

d

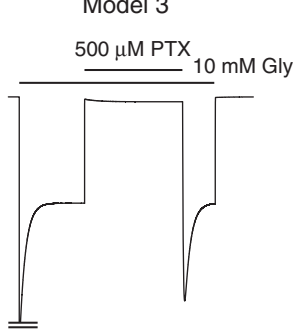

Figure 7 | GlyR current recovery after blockade by PTX under desensitizing conditions. (a) Representative recording of the fast dissociation of PTX from GlyR $\alpha 1$ activated by high concentrations $(10 \mathrm{mM})$ of glycine, accompanied by a clear rebound current $(n=5)$. (b-d) Predicted membrane currents for activated wild-type GlyRa1 using the kinetic models 1-3, respectively, described in Fig. 6 . See Supplementary Table 2 for the numerical values of parameters. Note, peak currents are truncated for clarity. 
Specific mutations near the P-loop of these voltage-gated channels profoundly impact on slow inactivation, in a similar manner to the effects of the mutations described in this study for Cys-loop receptor desensitization ${ }^{38,39}$. Corroboration for the slow inactivation model of voltage-gated ion channels was obtained using pore-blockers, such as tetraethylammonium, which reduced slow inactivation of Shaker $\mathrm{K}^{+}$channels by a 'foot-in-the-door' mechanism, essentially by binding near the selectivity filter to prevent its physical collapse ${ }^{38,40}$. By analogy, we used the Cys-loop $\mathrm{Cl}^{-}$channel blocker PTX to prevent $\mathrm{GABA}_{\mathrm{A}} \mathrm{R}$ and GlyR desensitization, which accorded with there being a spatial overlap between the desensitization gate and the PTX-binding site in the ion channel. Of note, a recent study showed that, in the absence of GABA, PTX is trapped in the resting state and not in the desensitized state ${ }^{23}$, though prolonged GABA applications were not investigated, and it therefore remains possible that PTXbound receptors might desensitize in the presence of saturating concentrations of GABA. Indeed, all the models we depict (Fig. 6a-c) are consistent with the data in ref. 23. To extend this further, our experimental results show that PTX actually prevents desensitization even in the presence of saturating concentrations of GABA. Overall, our study identifies a new potential molecular mechanism in $\mathrm{GABA}_{\mathrm{A}} \mathrm{Rs}$ and GlyRs that underpins one of the most fundamental parameters in pharmacology, that of receptor desensitization. We also establish a strong parallel between Cys-loop receptor desensitization and the slow inactivation of voltage-gated $\mathrm{K}^{+}$and $\mathrm{Na}^{+}$channels, even though the structure and membrane topology of these tetrameric channels is completely different from pentameric Cys-loop receptors.

In this context, it is notable that a recent crystal structure for the GABA receptor $\beta 3$ homomer has been solved. Although it is considered not to be a physiological form of the $\mathrm{GABA}_{\mathrm{A}}$ receptor, being unable to be activated by $\mathrm{GABA}^{41}$, the crystallographic data also alludes to a constriction at the intracellular end of the ion channel pore as being representative of a desensitized state ${ }^{42}$.

Our model suggests that the desensitization of Cys-loop receptors involves a rearrangement of the M2/M3 interface. This concept would accommodate the effects of modulators binding within the M1/M2/M3 intrasubunit cavity of nAChRs, which prevent desensitization ${ }^{43-45}$. Our results therefore provide a rationale for the mechanism of action of these drugs, and could help in designing pharmaceutical compounds to modulate Cys-loop receptor function. This is likely to be beneficial since Cys-loop receptors are involved in many pathological conditions, such as addiction, anxiety, depression, neurodegenerative diseases and seizures ${ }^{46-48}$.

\footnotetext{
Methods

Molecular biology. Murine $\mathrm{GABA}_{\mathrm{A}} \mathrm{R} \alpha 1, \beta 2$ and $\gamma 2$ subunits and human $\rho 1$ subunits were subcloned into pRK5 at the EcoRI site. The human GlyR $\alpha 1$ subunit was subcloned into pRK5 between the EcoRI and the NotI sites. Most $\mathrm{GABA}_{\mathrm{A}}$ chimeric receptors were obtained by amplification following a four-step procedure: first, a PCR was performed to build the amino-terminal end of the construct with the forward primer SP6 $\left(5^{\prime}\right.$ to $3^{\prime}$ sequence: CACATACGATTTAGGTGACACTA TAG) and a reverse primer overlapping the junction between the parental DNAs, followed by DNA purification (QIAquick PCR purification kit, Qiagen). Second, a PCR was performed to build the $\mathrm{C}$-terminal end of the construct with the reverse primer P5 (CAGACATGATAAGATACATTGATGAG) and a forward primer overlapping the junction between the parental DNAs, followed by DNA purification. Third, the PCR products were assembled through a final PCR step using SP6 and P5, followed by DNA gel extraction (QIAquick gel extraction kit, Qiagen). Fourth, the end product was subcloned into pRK5 with the restriction enzymes ClaI and SalI (NEB), using T4 DNA ligase (Roche). See Supplementary Table 4 for the primer sequences and the DNA templates used for the chimeras molecular biology. Single-point mutants and some chimeric receptors with small sequence exchanges (less than eight residues) were constructed with a single PCR reaction using Phusion DNA polymerase (Thermoscientific), followed by DNA gel extraction, $5^{\prime}$ phosphorylation using polynucleotide kinase (NEB) and subsequent ligation. See Supplementary Table 5 for the primer sequences and the DNA templates used for these mutant receptors.
}

Two-electrode voltage clamp and analysis. Xenopus laevis oocytes expressing recombinant receptors were prepared, injected with complementary DNAs (cDNAs; at 1-30 ng $\mu \mathrm{L}^{-1}$ ), voltage clamped and recorded as described previously ${ }^{16}$. All compounds were purchased from Sigma. EDTA $(10 \mu \mathrm{M})$ was added to the OR2 solution when recording from oocytes expressing GlyRs to chelate contaminating $\mathrm{Zn}^{2+}$, which potentiates GlyR function ${ }^{49}$. Recordings were digitized at $500 \mathrm{~Hz}$ and filtered at $50 \mathrm{~Hz}$. Desensitizing currents were induced by $1 \mathrm{~min}$ agonist applications. The design of our recording chamber and the use of supersaturating concentrations of agonist enabled us to elicit currents with $20-80 \%$ rise times of 22 and $15 \mathrm{~ms}$ for wild-type $\alpha 1 \beta 2 \mathrm{GABA}_{\mathrm{A}} \mathrm{Rs}$ and GlyR $\alpha 1$, respectively. The extent of desensitization was determined as

$$
1-I_{\text {Residual }} / I_{\text {peak }},
$$

where $I_{\text {peak }}$ is the agonist-induced peak current and $I_{\text {Residual }}$ the residual of this current remaining at the end of the agonist application. Weighted decay time constants for desensitization were determined by fitting the desensitizing phase with two or three exponential components (Clampfit ver 8). Experiments that assessed the time period for recovery of the receptor from desensitization were performed by first driving the receptor into a profound desensitized state $(30 \mathrm{~s}$ exposure to millimolar GABA or glycine concentrations), then monitoring the recovery of peak currents ( $2 \mathrm{~s}$ exposures) repeated at 10, 20, 30, 45, 60, 90, 120, 300 and 600 -s intervals after the initial desensitizing exposure to the agonist.

To resolve even faster channel kinetics, we have performed rapid-application perfusion experiments with outside-out patches pulled from Xenopus laevis oocytes expressing $\mathrm{GABA}_{\mathrm{A}}$ Rs. Using a piezo-driven theta tube, we achieved $20-80 \%$ solution exchange times $<100 \mu \mathrm{s}$. At wild-type $\alpha 1 \beta 2 \mathrm{GABA}_{\mathrm{A}} \mathrm{Rs}$, a 3 -s exposure of $10 \mathrm{mM}$ GABA led to a current that desensitized almost completely and is described by three exponential components of $\sim 10,100$ and $500 \mathrm{~ms}$, consistent with published results obtained with recombinant receptors expressed in HEK cells ${ }^{2}$. Although the 10-ms component cannot be detected using two-electrode voltage clamp (TEVC), we should have resolved the 100-ms component using oocytes, given the 22-ms rise time for GABA-activated currents, and, because exponentials of this order were detected with some of our mutant receptors. However, we never resolved such a fast component at wild-type $\alpha 1 \beta 2 \mathrm{GABA}_{\mathrm{A}}$ Rs (fastest component was $\sim 1-2 s$ ). Furthermore, the almost complete extent of fast desensitization in most outside-out patches did not concur with the large currents obtained with TEVC after a few seconds of exposure to GABA. Interestingly, recent results demonstrate that, in whole-cell patch-clamp recordings, GABA- and glycinemediated currents decay much faster than their respective membrane conductances in the continuous presence of the agonist ${ }^{50}$. Since the decay rates of the currents were matched by the rates of change of internal $\mathrm{Cl}^{-}$concentration, such an observation led the authors to speculate that the fast decay of currents, initially thought to reflect desensitization, actually reflects a decrease in the driving force for $\mathrm{Cl}^{-}$ions. This effect is likely to be present in most patch-clamp experiments performed on small cells or outside-out patches, especially under high series resistance conditions. The oocyte is therefore a reliable model system to study the Cys-loop receptor desensitization. Of note, the slow conductance decay rates measured in ref. 50 are consistent with the desensitization kinetics we measure in TEVC at wild-type receptors.

Finally, as mentioned above, we used outside-out patches pulled from oocytes that expressed mutants showing increased rates of desensitization under TEVC. Unfortunately, we could not resolve any current from patches containing $\alpha 1 \beta 2^{\rho 1(\mathrm{M} 1-\mathrm{M} 2 \text { link) }}$ or $\alpha 1^{\mathrm{V} 251 \mathrm{~F}} \beta 2$ receptors, even though the 'parent' oocytes exhibited strong functional expression ( $>5 \mu \mathrm{A}$ peak GABA current). Moreover, using outside-out patches from oocytes expressing the mild mutant $\alpha 1^{\mathrm{G} 258 \mathrm{~A}} \beta 2 \mathrm{G} 254 \AA$, we rarely recorded currents, and only then of a few pA decaying fully within $100 \mathrm{~ms}$. For all these reasons, we discarded the fast-perfusion experiments.

HEK whole-cell patch-clamp recording. HEK cells were transiently transfected using the calcium phosphate precipitation method with cDNAs pre-mixed in a 1:1 ratio, with $4 \mu \mathrm{g}$ total cDNA applied to each per $22 \mathrm{~mm}$ coverslip. HEK cells were voltage clamped and recorded from as described previously ${ }^{51}$. Recordings were digitized and filtered at $6.5 \mathrm{kHz}$. Desensitizing currents were induced by $8 \mathrm{~s}$ applications of GABA $(3 \mathrm{mM})$. The use of a rapid U-tube perfusion system and the use of supersaturating concentrations of agonist enabled us to elicit currents with average $20-80 \%$ rise times of $<8 \mathrm{~ms}$ for wild-type $\alpha 1 \beta 2 \mathrm{GABA}_{\mathrm{A}} \mathrm{Rs}$. The extent of desensitization and weighted decay time constants were determined as for TEVC, up to $6 \mathrm{~s}$ after the start of GABA application.

3D molecular modelling and illustration. Modeller (ver 9.7 (ref. 52)) was used to build 3D homology models of the $\alpha 1 \beta 2$ heteromeric $\mathrm{GABA}_{\mathrm{A}} \mathrm{R}$ based on the crystal structure of GluCl (pdb 3RHW (ref. 14)). Structures were visualized with $\mathrm{Pymol}^{53}$. pore radii were calculated with MOLE ${ }^{54}$.

Kinetic modelling. Channelab (ver 2, Synaptosoft, GA) was used to build the virtual recordings in Figs 6 and 7. The binding and gating rate constants are broadly consistent with previously published values for $\mathrm{GABA}_{\mathrm{A}} \mathrm{Rs}$ and $\mathrm{GlyRs} \mathrm{s}^{51,55}$ The desensitization rates were chosen to account for the profile of our current 
recordings. We modelled the slow component of receptor desensitization, since this is the component that is observed in our long duration applications of agonist, which were used to gather receptors in the desensitized state. The dissociation rate for PTX used for $\mathrm{GABA}_{\mathrm{A}}$ Rs predicted a slow recovery of the current consistent with our recordings in low concentrations of GABA. The dissociation constant for PTX $\left(0.4 \mu \mathrm{M}\right.$ for $\mathrm{GABA}_{\mathrm{A}}$ Rs and $10 \mu \mathrm{M}$ for GlyRs) are consistent with published $\mathrm{IC}_{50}$ values $^{24,56}$

\section{References}

1. Katz, B. \& Thesleff, S. A study of the desensitization produced by acetylcholine at the motor end-plate. J. Physiol. 138, 63-80 (1957).

2. Papke, D., Gonzalez-Gutierrez, G. \& Grosman, C. Desensitization of neurotransmitter-gated ion channels during high-frequency stimulation: a comparative study of Cys-loop, AMPA and purinergic receptors. J. Physiol. 589, 1571-1585 (2011).

3. Bianchi, M. T. \& MacDonald, R. L. Slow phases of $\mathrm{GABA}_{\mathrm{A}}$ receptor desensitization: structural determinants and possible relevance for synaptic function. J. Physiol. 544, 3-18 (2002).

4. Heine, M. et al. Surface mobility of postsynaptic AMPARs tunes synaptic transmission. Science 320, 201-205 (2008).

5. Jones, M. V. \& Westbrook, G. L. The impact of receptor desensitization on fast synaptic transmission. Trends Neurosci. 19, 96-101 (1996).

6. Overstreet, L. S., Jones, M. V. \& Westbrook, G. L. Slow desensitization regulates the availability of synaptic $\mathrm{GABA}_{\mathrm{A}}$ receptors. J. Neurosci. 20, 7914-7921 (2000).

7. Smart, T. G. \& Paoletti, P. in The Synapse. (eds Sheng, M., Sabatini, B. L. \& Sudhof, T. C.) 191-216 (Cold Spring Harbor Laboratory Press, 2012).

8. Mayer, M. L. Glutamate receptors at atomic resolution. Nature 440, 456-462 (2006).

9. Plested, A. J. R. \& Mayer, M. L. Structure and mechanism of kainate receptor modulation by anions. Neuron 53, 829-841 (2007).

10. Meyerson, J. R. et al. Structural mechanism of glutamate receptor activation and desensitization. Nature 514, 328-334 (2014).

11. Sun, Y. et al. Mechanism of glutamate receptor desensitization. Nature 417, 245-253 (2002).

12. Corringer, P. J. et al. Structure and pharmacology of pentameric receptor channels: from bacteria to brain. Structure 20, 941-956 (2012).

13. Martinez-Torres, A., Demuro, A. \& Miledi, R. GABAp1/GABA $A \alpha 1$ receptor chimeras to study receptor desensitization. Proc. Natl Acad. Sci. USA 97, 3562-3566 (2000)

14. Hibbs, R. E. \& Gouaux, E. Principles of activation and permeation in an anion-selective Cys-loop receptor. Nature 474, 54-60 (2011).

15. Whiting, P. J., McKernan, R. M. \& Wafford, K. A. Structure and pharmacology of vertebrate $\mathrm{GABA}_{\mathrm{A}}$ receptor subtypes. Int. Rev. Neurobiol. 38, 95-138 (1995).

16. Gielen, M. C., Lumb, M. J. \& Smart, T. G. Benzodiazepines modulate GABA receptors by regulating the preactivation step after GABA binding. J. Neurosci. 32, 5707-5715 (2012).

17. Breitinger, H. G. et al. Molecular dynamics simulation links conformation of a pore-flanking region to hyperekplexia-related dysfunction of the inhibitory glycine receptor. Chem. Biol. 11, 1339-1350 (2004).

18. Bocquet, N. et al. X-ray structure of a pentameric ligand-gated ion channel in an apparently open conformation. Nature 457, 111-114 (2009).

19. Hilf, R. J. C. \& Dutzler, R. X-ray structure of a prokaryotic pentameric ligand-gated ion channel. Nature 452, 375-379 (2008).

20. Hilf, R. J. C. \& Dutzler, R. Structure of a potentially open state of a proton-activated pentameric ligand-gated ion channel. Nature 457, 115-118 (2009).

21. Auerbach, A. \& Akk, G. Desensitization of mouse nicotinic acetylcholine receptor channels. A two-gate mechanism. J. Gen. Physiol. 112, 181-197 (1998).

22. Purohit, Y. \& Grosman, C. Block of muscle nicotinic receptors by choline suggests that the activation and desensitization gates act as distinct molecular entities. J. Gen. Physiol. 127, 703-717 (2006).

23. Bali, M. \& Akabas, M. H. The location of a closed channel gate in the $\mathrm{GABA}_{\mathrm{A}}$ receptor channel. J. Gen. Physiol. 129, 145-159 (2007).

24. Lynch, J. W., Rajendra, S., Barry, P. H. \& Schofield, P. R. Mutations affecting the glycine receptor agonist transduction mechanism convert the competitive antagonist, Picrotoxin, into an allosteric potentiator. J. Biol. Chem. 270, 13799-13806 (1995).

25. Wang, D. S. et al. Mechanisms for picrotoxinin and picrotin blocks of $\alpha 2$ homomeric glycine receptors. J. Biol. Chem. 282, 16016-16035 (2007).

26. Gay, E. A., Giniatullin, R., Skorinkin, A. \& Yakel, J. L. Aromatic residues at position 55 of rat alpha7 nicotinic acetylcholine receptors are critical for maintaining rapid desensitization. J. Physiol. 586, 1105-1115 (2008).

27. Bouzat, C., Bartos, M., Corradi, J. \& Sine, S. M. The interface between extracellular and transmembrane domains of homomeric cys-loop receptors governs open-channel lifetime and rate of desensitization. J. Neurosci. 28, 7808-7819 (2008)
28. Wang, Q. \& Lynch, J. W. Activation and desensitization induce distinct conformational changes at the extracellular-transmembrane domain interface of the glycine receptor. J. Biol. Chem. 286, 38814-38824 (2011).

29. Miller, P. S. \& Smart, T. G. Binding, activation and modulation of Cys-loop receptors. Trends Pharmacol. Sci. 31, 161-174 (2010).

30. Velisetty, P., Chalamalasetti, S. V. \& Chakrapani, S. Conformational transitions underlying pore opening and desensitization in membrane-embedded gloeobacter violaceus ligand-gated ion channel (GLIC). J. Biol. Chem. 287, 36864-36872 (2012).

31. Hustedt, E. J. \& Beth, A. H. Nitroxide spin-spin interactions: applications to protein structure and dynamics. Annu. Rev. Biophys. Biomol. Struct. 28, 129-153 (1999).

32. Althoff, T., Hibbs, R. E., Banerjee, S. \& Gouaux, E. X-ray structures of GluCl in apo states reveal a gating mechanism of Cys-loop receptors. Nature 512, 333-337 (2014).

33. Sine, S. M. \& Engel, A. G. Recent advances in Cys-loop receptor structure and function. Nature 440, 448-455 (2006).

34. Keramidas, A., Moorhouse, A. J., Schofield, P. R. \& Barry, P. H. Ligand-gated ion channels: mechanisms underlying ion selectivity. Prog. Biophys. Mol. Biol. 86, 161-204 (2004)

35. Cuello, L. G., Jogini, V., Cortes, D. M. \& Perozo, E. Structural mechanism of C-type inactivation in $\mathrm{K}^{+}$channels. Nature 466, 203-208 (2010).

36. Payandeh, J., Gamal El-Din, T. M., Scheuer, T., Zheng, N. \& Catterall, W. A. Crystal structure of a voltage-gated sodium channel in two potentially inactivated states. Nature 486, 135-139 (2012).

37. Zhang, X. et al. Crystal structure of an orthologue of the NaChBac voltagegated sodium channel. Nature 486, 130-134 (2012).

38. Kurata, H. T. \& Fedida, D. A structural interpretation of voltage-gated potassium channel inactivation. Prog. Biophys. Mol. Biol. 92, 185-208 (2006).

39. Lopez-Barneo, J., Hoshi, T., Heinemann, S. H. \& Aldrich, R. W. Effects of external cations and mutations in the pore region on C-type inactivation of Shaker potassium channels. Receptors Channels 1, 61-71 (1993).

40. Choi, K. L., Aldrich, R. W. \& Yellen, G. Tetraethylammonium blockade distinguishes two inactivation mechanisms in voltage-activated $\mathrm{K}+$ channels. Proc. Natl Acad. Sci. USA 88, 5092-5095 (1991).

41. Wooltorton, J. R., Moss, S. J. \& Smart, T. G. Pharmacological and physiological characterization of murine homomeric $\beta 3 \mathrm{GABA}_{\mathrm{A}}$ receptors. Eur. J. Neurosci. 9, 2225-2235 (1997).

42. Miller, P. S. \& Aricescu, A. R. Crystal structure of a human GABA receptor. Nature 512, 270-275 (2014).

43. daCosta, C. J., Free, C. R., Corradi, J., Bouzat, C. \& Sine, S. M. Single-channel and structural foundations of neuronal $\alpha 7$ acetylcholine receptor potentiation. J. Neurosci. 31, 13870-13879 (2011).

44. Gill, J. K. et al. Agonist activation of $\alpha 7$ nicotinic acetylcholine receptors via an allosteric transmembrane site. Proc. Natl Acad. Sci. USA 108, 5867-5872 (2011).

45. Williams, D. K., Wang, J. \& Papke, R. L. Investigation of the molecular mechanism of the $\alpha 7$ nicotinic acetylcholine receptor positive allosteric modulator PNU-120596 provides evidence for two distinct desensitized states. Mol. Pharmacol. 80, 1013-1032 (2011).

46. Changeux, J. P. Nicotine addiction and nicotinic receptors: lessons from genetically modified mice. Nat. Rev. Neurosci. 11, 389-401 (2010).

47. Galanopoulou, A. Mutations affecting GABAergic signaling in seizures and epilepsy. Pflügers Arch. 460, 505-523 (2010).

48. Mohler, H. The GABA system in anxiety and depression and its therapeutic potential. Neuropharmacology 62, 42-53 (2012).

49. Miller, P. S., Da Silva, H. M. \& Smart, T. G. Molecular basis for zinc potentiation at strychnine-sensitive glycine receptors. J. Biol. Chem. 280, 37877-37884 (2005).

50. Karlsson, U., Druzin, M. \& Johansson, S. $\mathrm{Cl}^{-}$concentration changes and desensitization of $\mathrm{GABA}_{\mathrm{A}}$ and glycine receptors. J. Gen. Physiol. 138, 609-626 (2011).

51. Mortensen, M., Ebert, B., Wafford, K. \& Smart, T. G. Distinct activities of GABA agonists at synaptic- and extrasynaptic-type $\mathrm{GABA}_{\mathrm{A}}$ receptors. J. Physiol. 588, 1251-1268 (2010).

52. Eswar, N., Eramian, D., Webb, B., Shen, M. Y. \& Sali, A. Protein structure modeling with MODELLER. Methods Mol. Biol. 426, 145-159 (2008).

53. DeLano, W. L. The PyMOL Molecular Graphics System (DeLano Scientific, 2002).

54. Petrek, M., Kosinova, P., Koca, J. \& Otyepka, M. MOLE: a Voronoi diagram-based explorer of molecular channels, pores, and tunnels. Structure 15, 1357-1363 (2007).

55. Lape, R., Colquhoun, D. \& Sivilotti, L. G. On the nature of partial agonism in the nicotinic receptor superfamily. Nature 454, 722-727 (2008).

56. Krishek, B. J., Moss, S. J. \& Smart, T. G. A functional comparison of the antagonists bicuculline and picrotoxin at recombinant $\mathrm{GABA}_{\mathrm{A}}$ receptors. Neuropharmacol. 35, 1289-1298 (1996). 


\section{Acknowledgements}

We thank Guy Moss and members of the Smart Lab for comments on the study. This work was supported by the MRC (T.G.S.) and EU-FP7 consortium, Neurocypres (TGS) and by a Long-Term Fellowship from the Human Frontier Science Program (HFSP) to M.G.

\section{Author contributions}

M.G. performed the molecular biology and M.G. and P.T. performed and analysed the TEVC and the patch-clamp experiments. All authors discussed the results. M.G. and T.G.S. designed the study and all authors wrote the manuscript.

\section{Additional information}

Supplementary Information accompanies this paper at http://www.nature.com/ naturecommunications
Competing financial interests: The authors declare no competing financial interests.

Reprints and permission information is available online at http://npg.nature.com/ reprintsandpermissions/

How to cite this article: Gielen, M. et al. The desensitization gate of inhibitory Cys-loop receptors. Nat. Commun. 6:6829 doi: 10.1038/ncomms7829 (2015).

(c) (i) This work is licensed under a Creative Commons Attribution 4.0 International License. The images or other third party material in this article are included in the article's Creative Commons license, unless indicated otherwise in the credit line; if the material is not included under the Creative Commons license, users will need to obtain permission from the license holder to reproduce the material. To view a copy of this license, visit http://creativecommons.org/licenses/by/4.0/ 